Perceiving the lengths of rods wielded in different media.

C.C. PAGANO \& K.G. DONAHUE-

(C.C.P.) Department of Psychology, 418 Brackett Hall, Clemson Univ., Box 341511, Clemson, SC 296341511; cpagano@clemson.edu

Judgments of perceptual groups: Reliability and sensitivity to stimulus transformation.

B.J. COMPTON \& G.D. LOGAN-

(B.J.C.) Department of Psychology, University of California, San Diego, 9500 Gilman Drive, La Jolla, CA 92093-0109; bcompton@ucsd.edu

Neural dynamics of perceptual order and context effects for variable-rate speech syllables.

I. BOARDMAN, S. GROSSBERG, C. MYERS, \& M. COHEN-

(S.G.) Dept. of Cognitive \& Neural Systems, Boston University, 677 Beacon Street, Boston, MA 02215; diana@cns.bu.edu

Interactions between perceptual organization based on Gestalt laws and those based on hierarchical processing.

S. HAN \& G.W. HUMPHREYS-

(S.H.) Beijing Lab of Cognitive Science, Univ. of Science \& Tech. of China, 19A Yuquan Road,

P.O. Box 3908, Beijing 100039, China; shhan@public2.bta.net.cn

Do the global advantage and interference effects co-vary?

G. AMIRKHIABANI \& W.J. LOVEGROVE-

(G.A.) Faculty of Arts, Health and Science, Central Queensland University, Rockhampton, QLD, 4702, Australia; a.keen@cqu.edu.au

An event-related brain potential study of inhibition of return.

J.J. MCDONALD, L.M. WARD, \& K.A. KIEHL-

(J.J.M.) Department of Psychology, University of British Columbia, 2136 West Mall, Vancouver,

BC V6T 1Z4, Canada; johnj@unixg.ubc.ca

Perception of artificial stereoscopic stimuli from an incorrect viewing point.

Y. BEREBY-MEYER, D. LEISER, \& J. MEYER-

(Y.B.) Department of Education, Ben-Gurion University of the Negev, 84105 Beer Sheva, Israel;

yoella@bgumail.bgu.ac.il

\title{
39th Annual Meeting of the Psychonomic Society \\ Dallas, Texas \\ November 19-22, 1998
}

The 39th Annual Meeting of the Psychonomic Society will be held in Dallas, Texas, at the Wyndham Anatole Hotel. Registration will begin on Thursday evening, November 19. A poster session will be held on Thursday evening; spoken sessions will begin on the morning of Friday, November 20. Sessions will continue through noon on Sunday, November 22.

Programs and hotel reservation cards were mailed to members and associates in the beginning of September. Additional programs will be available at the meeting registration desk for $\$ 10.00$.

For further information, please contact the Secretary-Treasurer of the Society: Roger L. Mellgren, Department of Psychology, Box 19528, University of Texas, Arlington, TX 76019-0528 (phone: 817-272-2775; fax: 817-272-2364; e-mail: mellgren@uta.edu). 